\title{
Evidence for a magnesium-insensitive membrane resistance increase during NMDA-induced depolarizations in rat neocortical neurons in vitro
}

\author{
Bernd Sutor*, Walter Jordan and Walter Zieglgänsberger \\ Clinical Neuropharmacology, Max-Planck-Institute for Psychiatry, Munich (F.R.G.) \\ (Received 11 November 1986; Revised version received 8 December 1986; Accepted 10 December 1986) \\ Key words: N-Methyl-D-aspartic acid; Magnesium; Intracellular recording; Membrane resistance; Corti- \\ cal neuron; Glutamate; Quisqualate; Rat
}

The responses of rat neocortical neurons in vitro to iontophoretically applied $N$-methyl-D-aspartate (NMDA) were investigated by means of intracellular recording in the presence and absence of extracellular magnesium jons $\left(\mathrm{Mg}^{2+}\right.$ ). At $\mathrm{Mg}^{2+}$-concentrations of $1.3 \mathrm{mM}$ the neurons responded with a depolarization accompanied by an increase in membrane resistance. Upon removal of $\mathrm{Mg}^{2+}$ the NMDA-induced depolarization was markedly potentiated. However, even in neurons recorded from slices which were incubated in a $\mathrm{Mg}^{2+}$-free solution for 3-7 h, the NMDA response was still associated with a resistance increase. suggesting that the voltage-dependence of the NMDA-activated conductance is not exclusively determined by $\mathrm{Mg}^{2+}$.

The depolarizing action of the excitatory amino acid $N$-methyl-D-aspartate (NMDA) on neurons of the mammalian central nervous system (CNS), including neocortical neurons, is associated with an apparent membrane resistance increase [ 1 $6,9,10,13,14]$. This conductance decrease was explained by the voltage-dependent activation of a cation $\left(\mathrm{Na}^{+}, \mathrm{Ca}^{2+}\right)$-selective channel $[7,9]$ coupled to the NMDAreceptor. Because upon removal of extracellular magnesium ions $\left(\mathrm{Mg}^{2+}\right)$ the NMDA-activated conductance $\left(g_{\mathrm{NMDA}}\right)$ became independent of the membrane potential, it was suggested that the voltage dependence of $g_{\mathrm{NMDA}}$ is produced by $\mathrm{Mg}^{2+}$, which, at physiological concentrations, reduces or blocks $g_{\mathrm{NMDA}}$ at membrane potentials larger than -40 to $-50 \mathrm{mV}$ [9-11]. In contrast, it has been proposed that NMDA either activates a voltage-dependent Ca-conductance (ref. 2, but see ref. 4) or a TTX-resistant, voltage-dependent Na-conductance $[3,8]$. Previous intracellular investigations of the actions of NMDA on rat neocortical neurons in vitro suggested

\footnotetext{
*Present address: Department of Neurology, Section of Neurophysiology, Baylor College of Medicine. Houston, TX 77030. U.S.A.

Correspondence: W. Zieglgänsberger, Clinical Neuropharmacology, Max-Planck-Institute for Psychiatry, Kracpelinstrassc 2. D-8000 München 40, F.R.G.
} 
that NMDA excites these neurons by activating a $\mathrm{Mg}^{2+}$-sensitive, voltage-dependent conductance $[13,14]$. Consequently, following the removal of extracellular $\mathrm{Mg}^{2+}$, the NMDA-induced depolarization should be associated with a membrane resistance decrease (see ref. 1). However, the present study, concerned with rat neocortical neurons in vitro, shows that NMDA induces membrane potential depolarizations accompanied by a resistance increase even in neurons recorded from slices which were kept in a $\mathrm{Mg}^{2+}$-free solution for $3-7 \mathrm{~h}$.

Slices $(500 \mu \mathrm{m})$ were prepared from the frontal cortex of Sprague--Dawley rats $(120-160 \mathrm{~g})$, transferred to the recording chamber, and maintained at the interface between warm humidified carbogen $\left(95 \% \mathrm{O}_{2} / 5 \% \mathrm{CO}_{2}\right)$ and artificial cerebrospinal fluid (ACSF) at 36-37 C. The ACSF consisted of (in $\mathrm{mM}$ ): $\mathrm{NaCl} 124.25, \mathrm{KCl} 3.5$, $\mathrm{NaH}_{2} \mathrm{PO}_{4} 1.25, \mathrm{CaCl}_{2} 2.5, \mathrm{MgSO}_{4} 1.3, \mathrm{NaHCO}_{3} 26$, and glucose 10 (gassed continuously with carbogen; final $\mathrm{pH}$ 7.4). Intracellular recordings were obtained from superficially located cortical neurons by means of microelectrodes filled with $4 \mathrm{M}$ potassium acetate ( $\mathrm{pH}$ 7.2). Potential recordings and current injections were performed using the switched current clamp mode of a single electrode current and voltage clamp amplifier (npi SEC 1L, 12). NMDA (20 mM, dissolved in $150 \mathrm{mM}$ sodium phosphate buffer, pH 8.0), Monosodium-L-glutamate (Glu, 1 M, pH 8.0), and Quisqualic acid (Quis, $20 \mathrm{mM}$ in sodium phosphate buffer, $\mathrm{pH} 8.0$ ) were administered by iontophoresis from 4-barrelled micropipettes positioned in close proximity to the recording electrode. Iontophoretic currents were compensated for via a barrel containing I $\mathrm{M} \mathrm{NaCl}$ and backing currents (5-10 nA) were employed to avoid spontaneous leakage of substances. Each amino acid was applied repetitively in a fixed cycle and measurements were performed after a stable reproducible response was attained.

The effects of the reduction in the extracellular $\mathrm{Mg}^{2+}$-concentration on the responses of cortical neurons to iontophoretically applied NMDA were investigated in 20 cells (resting membrane potential $\left(E_{\mathrm{m}}\right)$ : $-79.1 \pm 4.9 \mathrm{mV}$ (mean \pm S.D.), input resistance $\left(R_{\mathrm{N}}\right): 24.9 \pm 8.3 \mathrm{M} \Omega$, action potential amplitude: $104.1 \pm 6.3 \mathrm{mV}$ ). The current-voltage curves of all neurons revealed a marked inward rectification in a range between the $E_{\mathrm{m}}$ and potentials slightly negative to the spike threshold. The iontophoretic application of NMDA $(10-40 \mathrm{nA}$ for $5-15 \mathrm{~s})$ produced a slowly rising depolarization accompanied by a considerable increase in $R_{\mathrm{N}}(80-130 \%$, Fig. 1, control). This $R_{\mathrm{N}}$ increase was detectable even during NMDA-induced depolarizations of small amplitude $(5-10 \mathrm{mV})$, and was always more pronounced than that measured during passive depolarization of the membrane. In addition, NMDA-evoked repetitive fast depolarizing shifts (DS) which invariably triggered bursts of action potentials. Several minutes (4-7) after the replacement of the ACSF by a $\mathrm{Mg}^{2+}$-free solution, a dramatic enhancement of the NMDA-induced depolarization was observed in all neurons tested ( $n=15$, Fig. $1,0 \mathrm{mM} \mathrm{Mg}, 6 \mathrm{~min}$ ). To avoid irreversible depolarizations the NMDA dose had to be reduced (Fig. $1,0 \mathrm{mM} \mathrm{Mg}, 28 \mathrm{~min}$ ), and after approximately $30 \mathrm{~min}$ the iontophoretic current necessary to produce responses similar to those observed under control conditions was found to be decreased by $60-90 \%$ (Fig. 1, 0. mM Mg, $30 \mathrm{~min}$ ). However, the NMDA-induced depolarization was still accompanied by an increase in $R_{\mathrm{N}}$ (Fig. $1,0 \mathrm{mM} \mathrm{Mg}, 43 \mathrm{~min}$ ) which was larger than 

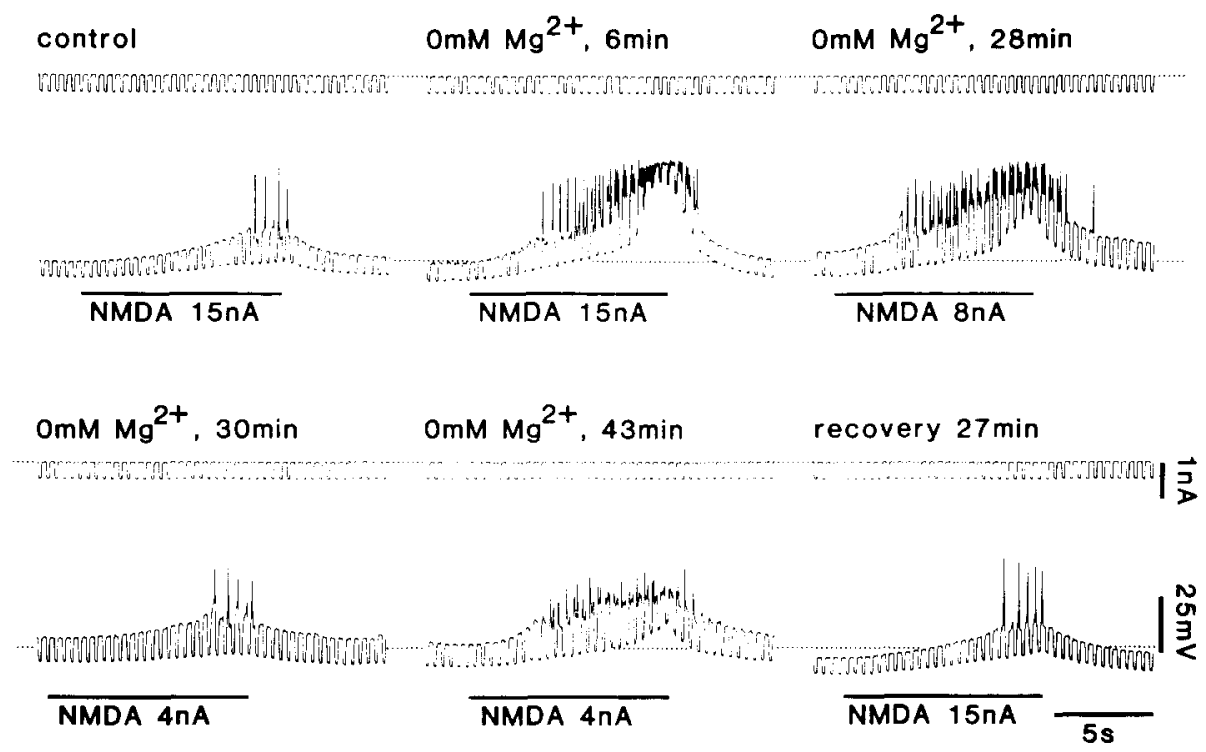

Fig. I. Actions of iontophoretically applied NMDA (4, 8, $15 \mathrm{nA}$ for 10 s) on the membrane potentials and resistance of an intracellularly recorded neuron $\left(E_{\mathrm{m}}\right.$ at control: $-81 \mathrm{mV}$, dotted line) before (control) and after the removal of extracellular $\mathrm{Mg}^{2+}\left(0 \mathrm{mM} \mathrm{Mg}{ }^{2+}, 643 \mathrm{~min}\right)$. In this and the following figures the upper trace represents the current monitor (adjusted to the extracellular zero potential), the lower trace the recorded membrane potential. The resistance was determined by measuring the steady-state voltage deviation due to a hyperpolarizing current pulse $(0.5 \mathrm{nA}$ for $150 \mathrm{~ms}$ at $2.5 \mathrm{~Hz})$. Note the slight depolarization and the $R_{\mathrm{V}}$ increase in the absence of $\mathrm{Mg}^{2+}$ and the hyperpolarization following the addition of $\mathrm{Mg}^{2}+$ to the ACSF (recovery. $27 \mathrm{~min}$ ). Action potentials are cut off.

that due to anomalous rectification. At the same time. Glu- and Quis-evoked depolarizations remained unaltered (Sutor et al, in preparation). The potentiation of the NMDA response in the absence of $\mathrm{Mg}^{2+}$ was associated with a small depolarization of the $E_{\mathrm{m}}(3-8 \mathrm{mV})$, an increase in $R_{\mathrm{N}}$ by $30-50 \%$, and spotaneous DS. Following the addition of normal $\mathrm{Mg}^{2+}$-concentrations to the ACSF all the described effects reversed. This recovery occurred simultaneously with a long-lasting hyperpolarization (3-6 mV for 15-40 min, Fig. 1, recovery, $27 \mathrm{~min}$ ). Increasing the extracellular $\mathrm{Mg}^{2+}$-concentration to $5 \mathrm{mM}$ resulted in a reversible diminution of the NMDAinduced depolarization $(n=6)$. The selective NMDA receptor antagonist D-2-amino5-phosphonovaleric acid (D-2-APV), added to the ACSF at concentrations of 5-50) $\mu \mathrm{M}$, reversibly blocked the actions of NMDA, both in the presence and absence of $\mathrm{Mg}^{2+}$.

NMDA responses are antagonized by $\mathrm{Mg}^{2+}$ at micromolar concentrations [11]. Therefore it may be that in our experiments the $\mathrm{Mg}^{2+}$-concentration was still sufficiently high to block NMDA-activated channels, even after prolonged perfusion (more than $60 \mathrm{~min}$; see also refs, 4, 13, 14, 15) with $\mathrm{Mg}^{2+}$-free solution using flow rates of $3-5 \mathrm{ml} / \mathrm{min}$ (chamber volume $0.8 \mathrm{ml}$ ). To test this possibility, slices were incubated in a $\mathrm{Mg}^{2+}$-free medium for 3-7 h prior to recording [4]. Due to the impurity of the analar grade salt compounds employed, this ' $\mathrm{Mg}^{2+}$-free' solution contained 


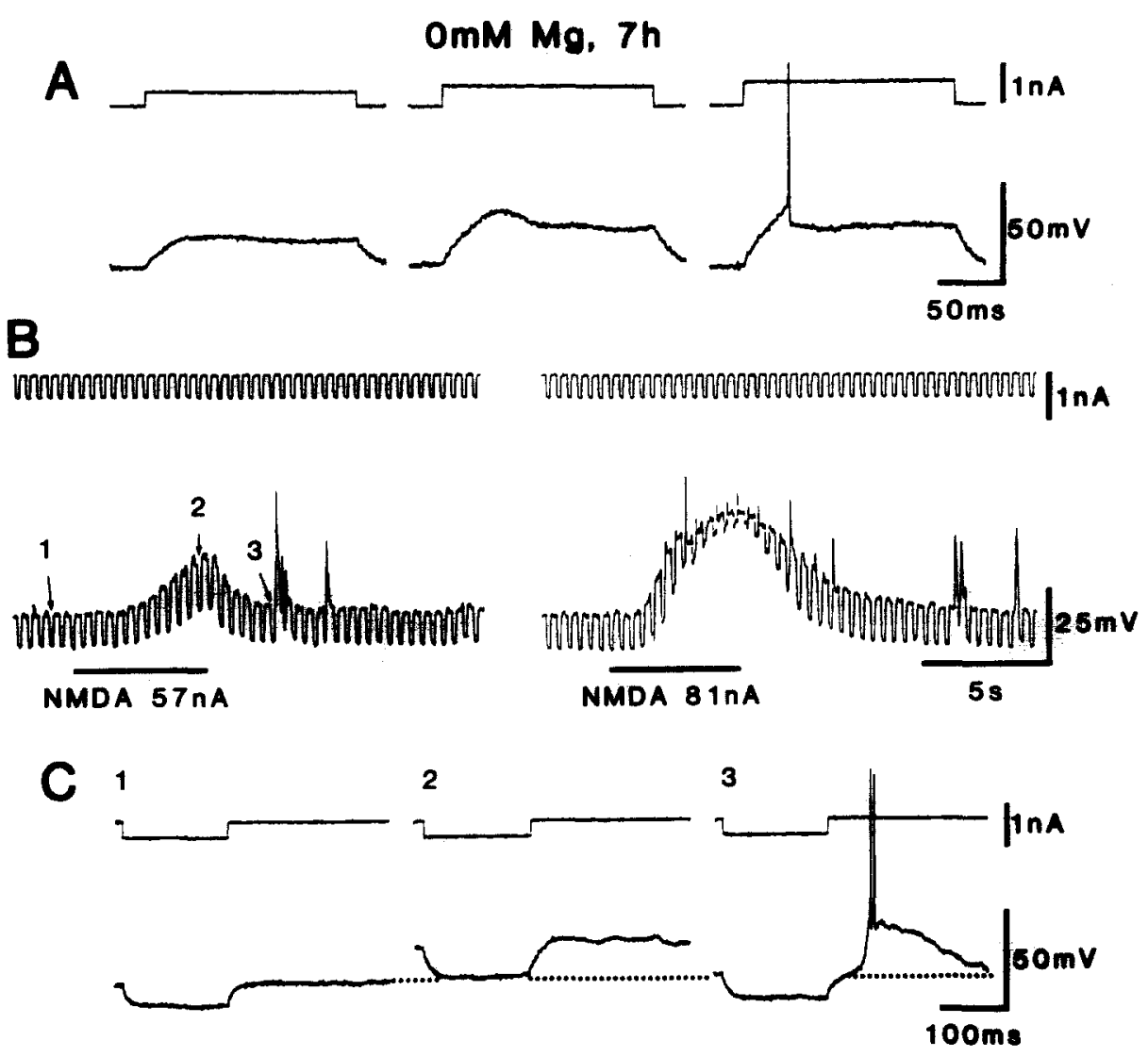

Fig. 2. Responses of a neuron to direct stimulation (A) and to iontophoretic application of NMDA (B, $\mathrm{C}$ ) in the absence of $\mathrm{Mg}^{2+}$ for $7 \mathrm{~h}$. $\mathrm{A}$ : injections of depolarizing current pulses $(150 \mathrm{~ms})$ with increasing amplitudes $(0.4,0.5,0.6 \mathrm{nA}$, left to right) evoked graded depolarizing voltage responses and an action potential respectively. Note the transient depolarizing potential occurring shortly after the onset of a current pulse with $0.5 \mathrm{nA}$ (resting membrane potential: $-79 \mathrm{mV}$ ). B: iontophoretically applied NMDA (57 $\mathrm{nA}$ (left) and $81 \mathrm{nA}$ (right) for $5 \mathrm{~s}$ ) induced depolarizations accompanied by increases in $R_{\mathrm{N}}$. During NMDA $(81 \mathrm{nA})$ the initial $\boldsymbol{R}_{\mathrm{N}}$ increase was followed by a net decrease. The vertical deflections during the potential recordings reflect spontaneous DS, typically generated by the neurons in the absence of $\mathrm{Mg}^{2+}$. C: single $R_{\mathrm{N}}$ measurements before (1), during (2), and after (3) the application of NMDA with $57 \mathrm{nA}$ for $5 \mathrm{~s}$ (same neuron as in $\mathrm{B}$, the numbers indicate the corresponding recordings). The $R_{\mathrm{N}}$ was determined at a frequency of $2.5 \mathrm{~Hz}$ using a hyperpolarizing current pulse $(0.3 \mathrm{nA}, 150 \mathrm{~ms})$. Note the large $(28 \mathrm{mV})$ spontaneous depolarizing shift, which triggered a doublet of action potentials $\left(\mathrm{C}_{3}\right)$.

$\mathrm{Mg}^{2+}$ in concentrations of 5-8 $\mu \mathrm{M}$, as determined by atomic absorption spectroscopy (see also ref. 9). Under such conditions, stable intracellular recordings were obtained from 5 neurons $\left(E_{\mathrm{m}}, R_{\mathrm{N}}\right.$, and spike amplitude were not significantly different from the control group, Fig. 2A). These neurons typically generated spontaneous repetitive fast DS capable of triggering spikes or bursts of spikes (Fig. $2 \mathrm{~B}$ and $2 \mathrm{C}_{3}$ ). At low to medium doses ( $57 \mathrm{nA}$, Fig. 2B) iontophoretically applied NMDA evoked a depolarization and an increase in $R_{\mathrm{N}}$ by $80-100 \%$. Using higher doses (Fig. 2B and 

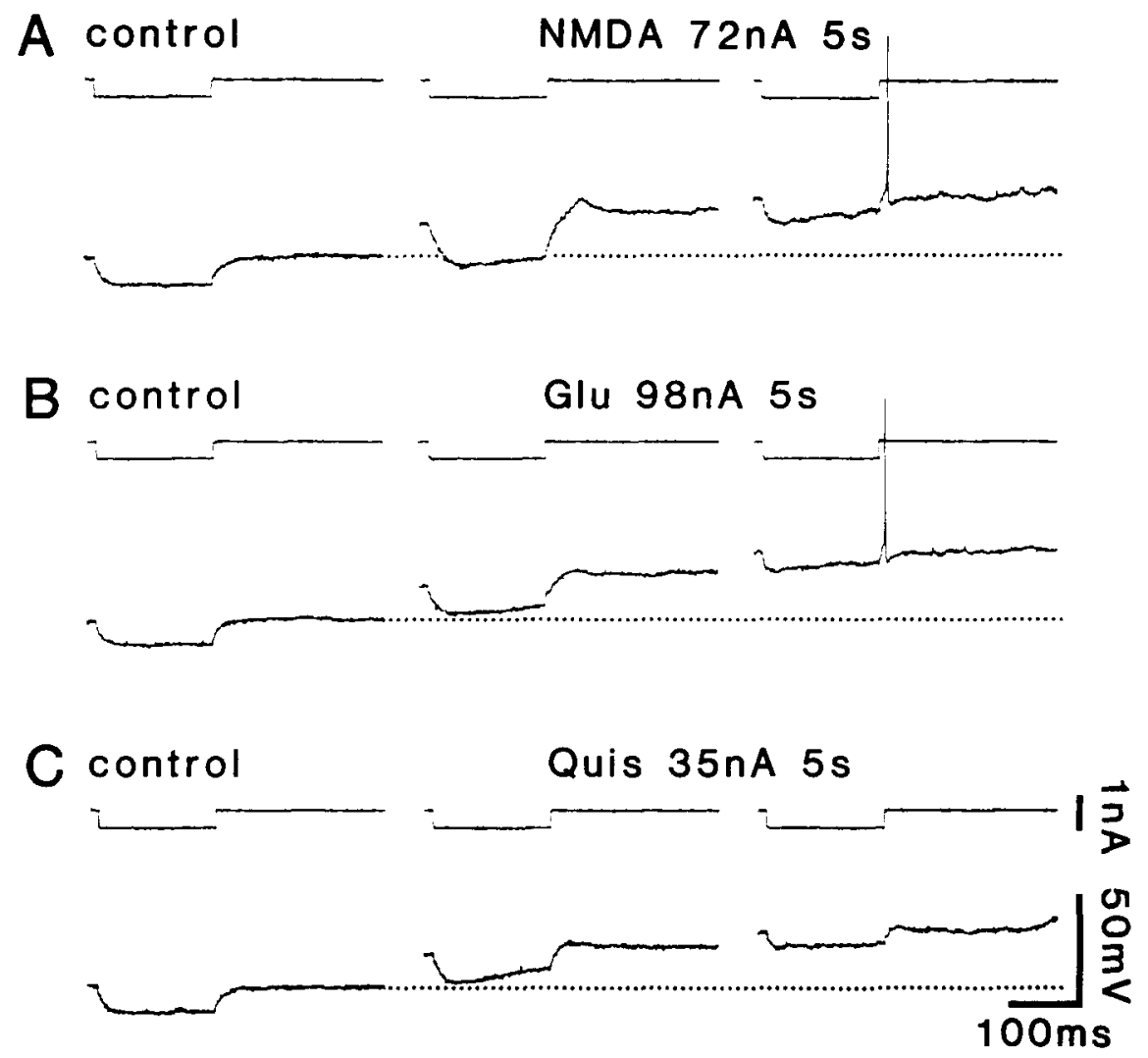

Fig. 3. Actions of iontophoretically applied amino acids on the membrane resistance of an intracellularly recorded neuron ( $E_{\mathrm{m}}$ : $-80 \mathrm{mV}$, indicated by the dotted lines) in the absence of $\mathrm{Mg}^{2+}(4 \mathrm{~h})$. A: NMDA (72 $\mathrm{nA}, 5 \mathrm{~s}$ ) depolarized the membrane potential by $14 \mathrm{mV}$ (middle, $2 \mathrm{~s}$ after onset of application) and $24 \mathrm{mV}$ (right. $4 \mathrm{~s}$ after onset). Simultaneously, the resistance increased from $26 \mathrm{M} \Omega$ (control, left) to 51 $\mathrm{M} \Omega$ (middle) and decreased with further depolarization to $19 \mathrm{M} \Omega$ (right). The calculated rectification ratios (RR) were 1.96 (depolarization by $14 \mathrm{mV}$ ) and 0.8 (depolarization by $24 \mathrm{mV}$ ) respectively. During passive depolarization of the membrane the resistance increased from 26 to $39 \mathrm{M} \Omega$, i.e. $\mathrm{RR}=1.5$. (Resistance measurement with inward current pulses (150 ms, $0.4 \mathrm{nA}$ ) applied at $2.5 \mathrm{~Hz}$.) B: Glu (98 nA, $5 \mathrm{~s})$ induced a depolarization by $15 \mathrm{mV}(1.2 \mathrm{~s}$ after onset, middle) and $29 \mathrm{mV}$ ( $4 \mathrm{~s}$ after onset, right) associated with a resistance increase from $26 \mathrm{M} \Omega$ (control) to $34 \mathrm{M} \Omega$ (depolarization by $15 \mathrm{mV}$, middle), followed by a decrease to $17 \mathrm{M} \Omega$ (depolarization by $29 \mathrm{mV}$, right). $\mathrm{RR}=1.3(15 \mathrm{mV})$ and $0.7(29 \mathrm{mV}$ ) respectively. C: Quis (35 nA, $5 \mathrm{~s})$ evoked a membrane depolarization of $14 \mathrm{mV}(0.9 \mathrm{~s}$ after onset, middle) and $25 \mathrm{mV}$ (4 s after onset, right). No steady-state resistance change could be detected after the membrane was depolarized by $14 \mathrm{mV}$ (i.e. $\mathrm{RR}=1$, middle). Further depolarization resulted in a resistance decrease (from 26 $\mathrm{M} \Omega$ (control) to $17 \mathrm{M} \Omega$ (right), $\mathrm{RR}=0.7$ ).

Fig. 3) the initial $R_{\mathrm{N}}$ increase was followed by a net decrease. Fig. 3 demonstrates that the $R_{N}$ increase during the initial phase of the NMDA-induced depolarization was not solely due to the inward rectification present in these neurons. At comparable levels of depolarization (Fig. 3, middle column, amino acid-induced depolarizations by $14-16 \mathrm{mV}$ ) the voltage change produced by a hyperpolarizing current pulse was clearly larger during the NMDA response than during the depolarizations 
evoked by Glu or Quis. Furthermore, the rectification ratio (i.e. $R_{\mathrm{N}}$ during passive depolarization $/ \boldsymbol{R}_{\mathrm{N}}$ at resting potential) of this neuron was found to be 1.5 during passive depolarization by $15 \mathrm{mV}$, and 1.9 during the NMDA-evoked depolarization. Similar results were obtained from all 5 neurons tested.

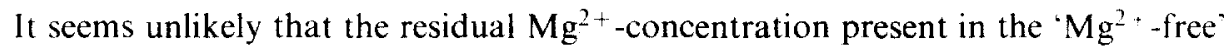
solution is still effectively blocking $g_{\mathrm{NMDA}}$, since the NMDA-induced depolarization was found to be strongly potentiated (Fig. 1) and, in addition, the neurons generated spontaneous DS (7-10/min, Fig. 2), which were considered to be due to a release of $g_{\mathrm{NMDA}}$ from the $\mathrm{Mg}^{2+}$-induced block $[13,15]$. Therefore, the present results indicate that the voltage dependence of the $g_{\mathrm{NMDA}}$, which was taken to explain the apparent membrane resistance increase during NMDA-induced membrane potential depolarizations of neocortical neurons in vitro [3], is probably not exclusively determined by a $\mathrm{Mg}^{2+}$-induced voltage-dependent block of the NMDA-sensitive channel.

This work was supported by the SFB 220, A5, of the Deutsche Forschungsgemeinschaft and by the BMFT.

1 Crunelli, V. and Mayer, M.L., $\mathrm{Mg}^{2+}$ dependence of membrane resistance increases evoked by NMDA in hippocampal neurones, Brain Res., 311 (1984) 392-396.

2 Dingledine, R., $N$-Methylaspartate activates voltage-dependent calcium conductance in rat hippocampal pyramidal cells, J. Physiol. (London), 343 (1983) $385-405$.

3 Flatman, J.A., Schwindt, P.C. and Crill, W.E., The induction and modification of voltage-sensitive responses in cat neocortical neurones by $N$-methyl--D-aspartate, Brain Res., 363 (1986) $62 \cdots 77$.

4 Hablitz, J.J., Action of excitatory amino acids and their antagonists on hippocampal neurons, Cell. Molec. Neurobiol., 5 (1985) 389-405.

5 Jordan, W., Sutor, B. and Zieglgänsberger, W., The action of L-glutamate, L-aspartate and $N$-methylD-aspartate (NMDA) on membrane potential and input resistance of rat neocortical neurons in vitro, Pflügers Arch., 405 (1985) R45.

6 Lambert, J.D.C., Flatman, J.A. and Engberg, I., Actions of excitatory amino acids on membrane conductance and potential in motoneurones. In G. DiChiara and G.L. Gessa (Eds.), Glutamate as a Neurotransmitter, Raven, New York, 1981, pp. 205-216.

7 MacDermott, A.B., Mayer, M.L., Westbrook, G.L., Smith, S.J. and Barker, J.L., NMDA-receptor activation increases cytoplasmic calcium concentration in cultured spinal cord neurones, Nature (London), 321 (1986) 519-522.

8 MacDonald, J.F., Porietis, A.V. and Wojtowicz, J.M., L-Aspartic acid induces a region of negative slope conductance in the current-voltage relationship of cultured spinal cord neurons, Brain Res., 237 (1982) $248 \cdots 253$.

9 Mayer, M.L. and Westbrook, G.L., The action of $N$-methyl-D-aspartic acid on mouse spinal neurons in culture, J. Physiol. (London), 361 (1985) 65-90.

10 Mayer, M.L., Westbrook, G.L. and Guthrie, P.B., Voltage-dependent block by $\mathrm{Mg}^{2+}$ of NMDA responses in spinal cord neurones, Nature (London), 309 (1984) 261-263.

11 Nowak, L.. Bregestovski, P., Ascher, P., Herbet, A. and Prochiantz, A., Magnesium gates glutamateactivated channels in mouse central neurones, Nature (London), 307 (1984) 462-465.

12 Polder. H.-R., Swandulla, D., Konnerth, A. and Lux, H.D., An improved, high current single electrode current/voltage clamp system, Pfügers Arch., 402 (1984) R35.

13 Thomson, A.M., A magnesium-sensitive postsynaptic potential in rat cerebral cortex resembles neuronal responses to $N$-methylaspartate, J. Physiol. (London), 370 (1986) $531-549$

14 Thomson, A.M., Comparison of responses to transmitter candidates at an $N$-methylaspartate receptormediated synapse, in slices of rat cerebral cortex, Neuroscience, 17 (1986) 37-47.

15 Walther, H., Lambert, J.D.C., Jones, R.S.G., Heinemann, U. and Hamon, B., Epileptiform activity in combined slices of the hippocampus, subiculum and entorhinal cortex during perfusion with low magnesium medium, Neurosci. Lett., 69 (1986) $156-161$. 